\title{
PEMBANGUNAN KARAKTER SISWA MELALUI HABITUASI SEKOLAH MUHAMMADIYAH (STUDI KASUS SMP MUHAMMADIYAH AL MUJAHIDIN WONOSARI)
}

\author{
Purwanto \\ Program Pasca Sarjana \\ Universitas Muhammadiyah Yogyakarta \\ E-mail: tipunk75@yahoo.com
}

\begin{abstract}
Abstrak
Kasus ini terlihat pada banyaknya perselisihan, perpecahan, bullying dan kasus lainnya. Gejala ini membutuhkan perhatian yang cukup serius bagi banyak kalangan, terutama dunia pendidikan. Terkaitan hal tersebut, peneliti tertarik pada SMP Muhammadiyah Al Mujahidin Wonosari salah satu lembaga pendidikan yang memperhatikan tentang pembangunan karakter siswa melalui habituasi (pembiasaan). Untuk menjawab pertanyaan tersebut peneliti menggunakan metode kualitatif dengan cara observasi, wawancara, dan dokumentasi. Adapun fakta di lapangan yang peneliti temukan adalah SMP Muhammadiyah Al Mujahidin menerapkan model fullday school dan boarding school, yang pernah meraih beberapa prestasi baik secara akademik maupun non akademik. Adapun didalam proses pembangunan karakter siswa di SMP Muhammadiyah Al Mujahidin menerapkan sistem habituasi yakni dengan cara pengembangan kurikulum dan berbagai kegiatan yang terprogram, seperti :(1) program Golden Habits Islami,(2) Program Gerakan literasi sekolah, (3) Program Apresiasi Cipta Adi Karya, (4)Program Student Exchange 2018 (Malaysia dan Thailand),(5) Program Bina Prestasi Tahun ajaran 2017-2021 (one student one trophy) dan (6) program Sukses UN \& USBN.
\end{abstract}

Kata kunci : pembangunan karakter, siswa dan habituasi

\begin{abstract}
This case is seen in the number of disputes, divisions, bullying and other cases. This phenomenon requires quite serious attention for many people, especially the world of education. Related to this, researchers are interested in Muhammadiyah Al Mujahidin Middle School, Wonosari, one of the educational institutions that pays attention to the development of student character through habituation (habituation). To answer these questions researchers used qualitative methods by observation, interview, and documentation. The facts on the ground that the researchers found were Muhammadiyah Al Mujahidin Middle School applying the full-day school and boarding school models, which had achieved several achievements both academically and non-academically. As for the character building process of students in Muhammadiyah Al Mujahidin Junior High School, the habituation system is implemented by developing curriculum and various programmed activities, such as: (1) the Golden Habits Islamic program, (2) the school literacy movement program, (3) the Cipta Adi Appreciation Program Karya, (4) 2018 Student Exchange Program (Malaysia and Thailand), (5) Achievement Development Program for the 2017-2021 academic year (one student one trophy) and (6) Successful UN \& USBN program.
\end{abstract}

Keywords: character building, students and habituation

\section{Info Artikel}

Diterima Januari 2020, disetujui Februari 2020, diterbitkan Juni 2020 


\section{PENDAHULUAN}

Pendidikan nasional berfungsi mengembangkan kemampuan dan membentuk watak serta peradaban bangsa yang bermartabat dalam rangka mencerdaskan kehidupan bangsa, bertujuan untuk berkembangnya potensi peserta didik agar menjadi manusia yang beriman dan bertakwa kepada Tuhan Yang Maha Esa, berakhlak mulia, sehat, berilmu, cakap, kreatif, mandiri, dan menjadi warga negara yang demokratis serta bertanggung jawab. (Pasal 3 UU. Sisdiknas). Menurut Ki Hajar Dewantara, pendidikan adalah daya upaya untuk memajukan bertumbuhnya budi pekerti (kekuatan batin, karakter), pikiran (intellect) dan tubuh anak. Bagian-bagian itu tidak boleh dipisahkan agar kita dapat memajukan kesempurnaan hidup anak-anak kita.

Namun, kondisi yang terjadi saat ini berbanding terbalik dengan kondisi yang diharapkan. Seperti yang diberitakan di Kedaulatan Rakyat (16/12/2017) analisis KR tentang bocah bahwa pelecehan dan pemerkosaan anak adalah salah bentuk pelanggaran hak anak yang sering terjadi di berbagai daerah. Kasus kekarasan seksual yang dialami anak-anak, umumnya dilakukan laki-laki dewasa yang memanfaatkan ketidakberdayaan korban. Tetapi kasus terakhir ini mengusik nurani. Seperti di daerah Bantul, dua bocah mungil yang masih duduk di bangku TK menjadi korban pencabulan seorang siswa SMP, Fr (13 tahun) yang memiliki kebiasaan menonton cyberporn lewat handphone (HP). Kemudian mengakses pornografi melalui gadget membuat anak laki-laki yang masih duduk di bangku SMP ini tumbuh lebih cepat dewasa daripada anak-anak seusianya yang lain. Kemudian maraknya tawuran antar pelajar, temperamen tumbuh di kalangan pelajar, perkelahian, begal, pemerkosaan, pencurian, berbohong, pornografi, kekerasan, pacaran di usia dini dan terjadi bullying. Berbagai persoalan sosial budaya yang muncul di masyarakat akhir-akhir ini mencemaskan para orang tua. Mereka bertanya bagaimana harus menyiapkan anak-anak agar memiliki bekal nilai yang cukup untuk terjun di masyarakat tanpa takut terseret arus dan menjadi korban sia-sia.

Dari data hasil pengaduan dan pengawasan KPAI terkait dengan kasus pendidikan tahun 2014 mencapai 461 kasus, dan tahun 2015 naik menjadi 478 kasus. Sementara bidang lain trennya menurun. Bidang pendidikan terjadi peningkatan sebesar 4\% (17 kasus). Sedangkan kasus anak yang menjadi pelaku bullying di satuan pendidikan meningkat. Anak yang menjadi pelaku bullying pada tahun 2014 sebanyak 
67 laporan, tahun 2015 meningkat menjadi 93 laporan, terjadi peningkatan sebesar 39\% (26 kasus), dan tahun 2016 terakhir 267 laporan .

Dari latar belakang tersebut, penulis bertujuan untuk mendiskripsikan pembangunan karakter melalui habituasi (pembiasaan) sekolah yang dibangun pada SMP Muhammadiyah Al Mujahidin di Wonosari. Yang dimana sekolah tersebut merupakan sekolah yang mengembangkan model Boarding School dan full day school. Hal ini menjadi penting untuk dikaji dan diteliti lebih mendalam dilihat dari habituasi sekolah, karena untuk mewujudkan pembangunan karakter siswa melalui habituasi atau pembiasaan sekolah sangat dibutuhkan komitmen dari warga sekolah. Warga sekolah perlu memiliki perilaku dan sikap yang peduli dalam membangun karakter siswa, sadar dan kemitmen dalam mewujudkan pendidikan karakter siswa di lembaga satuan pendidikan (sekolah) ini merupakan keharusan. Bahwa pembangunan karakter siswa di satuan pendidikan atau lembaga pendidikan erat kaitannya dengan "habit" atau kebiasaan yang di lakukan secara kontiyu.

\section{METODE PENELITIAN}

Metode penelitian yang digunakan dalam penelitian ini adalah metode kualitatif. Dalam penelitian kualitatif, pengumpulan data pada dilakukan pada natural setting (kondisi yang alamiah), sumber data primer, dan teknik pengumpulan data lebih banyak observasi berperanserta (participant observation), wawancara mendalam (in deph interview) dan dokumentasi. Analisis data dalam dalam penelitian kualitatif, dilakukan pada saat pengumpulan data berlangsung, dan setelah selesai pengumpulan data periode tertentu. Data yang terkumpul dianalisis dengan menggunakan teknik analisis induktif seperti dikemukan oleh Miles dan Huberman (1984). Analisis dilakukan dengan empat tahap, yaitu tahapan pengumpulan data, reduksi data, penyajian data, dan penarikan kesimpulan.

Dalam penelitian ini informan terdiri dari kepala sekolah, guru, tenaga kependidikan dan siswa. Lokasi penelitian adalah SMP Muhammadiyah Al Mujahidin Wonosari, dan sedangkan lama penelitian selama 3 hari dari mulai tanggal 7 Mei 2018 s.d 9 Mei 2018. Keabsahan hasil penelitian ini sudah di cek melalui turnitin 13\%. 


\section{HASIL DAN PEMBAHASAN}

Dari pengamatan dan dokumentasi bahwa keadaan karakter siswa di SMP Muhammadiyah Al Mujahidin Wonosari sudah menerapkan pola nilai kehidupan di sekolah dengan nilai sebagai berikut: a) religius, b) jujur, c) disiplin, d) mandiri, e) toleransi, f) tanggungjawab, g) kerendahan diri, h) kerja sama, i) kesederhanaan, j) kebahagiaan , k) cinta dan 1) kebebasan.

Kegiatan habituasi (pembiasaan) di SMP Muhammadiyah Al Mujahidin Wonosari dilaksanakan dengan cara terprogram dan dibukukan sebagai panduan setiap warga sekolah.

Adapun proses pembangunan karakter siswa di SMP Muhammadiyah Al Mujahidin Wonosari menerapkan sistem habituasi yakni dengan cara pengembangan kurikulum dan berbagai kegiatan yang terprogram, seperti: a) .Program Habits Islami, b) Program Gerakan Literasi Sekolah, c) Program Apresiasi Cipta Karya, d) Program Student Exchange, (Malaysia dan Thailand), e) Program Bina Prestasi tahun ajaran 2017-2021 (one student one trophy) dan f) Program Sukses UN \& USBN.

\section{KESIMPULAN}

Berdasarkan hasil penelitian dengan teknik observasi, wawancara, dan dokumentasi yang dilaksanakan di SMP Muhammadiyah Al Muhajidin Wonosari maka dapat di simpulkan:

a. Nilai Religius, Penghargaan, cinta, toleransi, kejujuran, kerendahan hati, kerjasama, kebahagiaan, tanggung jawab, kesederhanaan, kebebasaan dan persatuan. Nilai nilai tersebut dipraktekan dalam kehidupan sehari-hari siswa dan semua sivitas akademika sekolah, baik dituangkan dalam aturan tertulis maupun tidak tertulis, sehingga menjadi sebuah budaya sekolah.

b. Karakter siswa SMP Muhammadiyah Al Mujahidin Wonosari sudah terpola di dalam nilai kehidupan di sekolah tersebut dengan baik.

c. Kegiatan habituasi (pembiasaan) di SMP Muhammadiyah Al Mujahidin Wonosari dilaksanakan dengan cara terprogram dan dibukukan sebagai panduan setiap warga sekolah.

d. Adapun proses pembangunan karakter siswa di SMP Muhammadiyah Al Mujahidin Wonosari menerapkan sistem habituasi yakni dengan cara pengembangan 
kurikulum dan berbagai kegiatan yang terprogram, seperti: a) .Program Habits Islami, b) Program Gerakan Literasi Sekolah, c) Program Apresiasi Cipta Karya, d) Program Student Exchange, (Malaysia dan Thailand), e) Program Bina Prestasi tahun ajaran 2017-2021 (one student one trophy) dan f) Program Sukses UN \& USBN.

\section{DAFTAR PUSTAKA}

Chairul, A. 2014. "Internalisasi Semangat Nasionalisme melalui Pendekatan Habituasi (Perspektif Filsafat Pendidikan). Jurnal Studi Keislaman, Volume 14, Nomor 1, Juni 2014.

Dikdasmen PWM. 2015. Kumpulan Peraturan / Ketentuan di Lingkungan Pendidikan Dasar dan Menengah PWM D.I Yogyakarta. Yogyakarta: Percetakaan Muhammadiyah Gramasurya.

Hapsari, W dan Iftayani, I. 2016. Model Pendidikan Pada Anak Usia Dini melalui Program Islamic Habituation. 2016. Uuniversitas Muhammadiyah Purwakerto. Jurnal Indigenous Vol. 1 Tahun 2016.

Komalasari dan Saripudin, D. 2017. Pendidikan Karakter Konsep dan Aplikasi Living Values Education. Bandung. PT. Refika Aditama.

KPAI. 2016. Panduan Sekolah \& Madrasah Ramah Anak. Jakarta: Erlangga.

Kurniawan, S. 2017. Pendidikan Karakter: Konsep dan Implementasi secara terpadu di Lingkungan Keluarga, Sekolah, Perguruan Tinggi, dan Masyarakat. Yogyakarta: Ar-Ruzz Media.

Lickona, T. 2016. Educating For Character Mendidik Untuk Membentuk Karakter Bagaimana Sekolah Dapat Mengajarkan Sikat Hormat Dan Tanggung Jawab. Jakarta. Bumi Aksara.

Made, W. 2016. Strategi pembelajaran Inovatif Kontemporer Suatu Tinjaun Konseptual Operasional. Jakarta. Bumi aksara.

Muhammad, A. 2006. Pendidikan Agama Islam (Upaya Pembentukan Pemikiran dan Kepribadian Muslim). Bandung: Remaja Rosdakarya.

Musrifah. 2016. Pendidikan Karakter dalam Perspektif Islam”, Sekolah Tinggi Agama Islam (STAI) Brebes. Jurnal Edukasia Islamika: Volume I, Nomor 1, Desember 2016/1438.

Nunuk, S., Setiawan dan Putri, A. 2018. Media Pembelajaran Inovatif dan Pengembangan. Bandung. PT Remaja Rosdakarya. 
Samsuri dan Marzuk. 2016. "Pembentukan Karakter Kewargaan Multikultural Dalam Program Kurikulum di Madrasah Aliyah Se-daerah Istimewa Yogyakarta". Fakultas Ilmu Sosial UNY. Journal Cakrawala pendidikan, Februari 2016. Tahun XXXV, No. 1.

Sudarman, D., dan Khairil. 2014. Psikologi Pendidikan (Dalam Perspektif Baru). Bandung: Alfabeta.

Sugiyono. 2017. Metode Penelitian Pendidikan Pendekatan Kuantitatif, kualitatif, dan $R \& D$. Bandung. Alfabeta.

Suranto, A. W. 2016. "Nilai - Nilai Pendidikan Karakter Yang Terkandung Dalam Tayangan "Mario Teguh Golden Ways “: Fakultas Ilmu Sosial. UNY. Jurnal pendidikan Karakter. Tahun VI. Nomor 2. Oktober 2016.

Susanto, A. 2017. Proses Habituasi Nilai Disiplin pada anak usia dini dalam rangka pembentukan karakter bangsa" Jurnal Sosioreligi. Volume 15 Nomor 1, Edisi Maret 2017.

Sutarto, A. J., dan Ikhwanuddin. 2014. Model Pendidikan Karakter di SMK Melalui Program Pengembangan Diri dan Kultur Sekolah. Jurnal pendidikan Teknologi dan Kejuruan, Volume 22, Nomor 2. Oktober 2014. Yogyakarta: Fakultas Teknik UNY.

Syafri, U. A. 2014. Pendidikan Karakter Berbasis Al-Qur'an. Jakarta. Raja Grafindo Persada.

Ukim, K. 2015. Arief Rahman: Guru berdasarkan Catatan Ukim Komarudin. Jakarta: Esensi erlangga Group.

Yuliza, E. 2016. Upaya Bimbingan Konseling Dalam Pengembangan Karakter Siswa. STAI Hubbulwathan. Journal Pendidikan.

Zainal, A. 2017. Model-Model Media, dan Strategi Pembelajaran Kontekstual (Inovatif). Bandung. Yrama Widya. 